\title{
QUEEN'S
UNIVERSITY
BELFAST
}

\section{Optimal remediation design and simulation groundwater flow coupled to contaminant transport using genetic algorithm and radial point collocation method (RPCM)}

Seyedpour, S. M., Kirmizakis, P., Brennan, P., Doherty, R., \& Ricken, T. (2019). Optimal remediation design and simulation groundwater flow coupled to contaminant transport using genetic algorithm and radial point collocation method (RPCM). Science of the Total Environment, 669, 389-399.

https://doi.org/10.1016/j.scitotenv.2019.01.409, https://doi.org/10.1016/j.scitotenv.2019.01.409

\section{Published in:}

Science of the Total Environment

\section{Document Version:}

Peer reviewed version

Queen's University Belfast - Research Portal:

Link to publication record in Queen's University Belfast Research Portal

\section{Publisher rights}

Copyright 2019 Elsevier.

This manuscript is distributed under a Creative Commons Attribution-NonCommercial-NoDerivs License

(https://creativecommons.org/licenses/by-nc-nd/4.0/), which permits distribution and reproduction for non-commercial purposes, provided the author and source are cited.

\section{General rights}

Copyright for the publications made accessible via the Queen's University Belfast Research Portal is retained by the author(s) and / or other copyright owners and it is a condition of accessing these publications that users recognise and abide by the legal requirements associated with these rights.

Take down policy

The Research Portal is Queen's institutional repository that provides access to Queen's research output. Every effort has been made to ensure that content in the Research Portal does not infringe any person's rights, or applicable UK laws. If you discover content in the

Research Portal that you believe breaches copyright or violates any law, please contact openaccess@qub.ac.uk. 


\section{Accepted Manuscript}

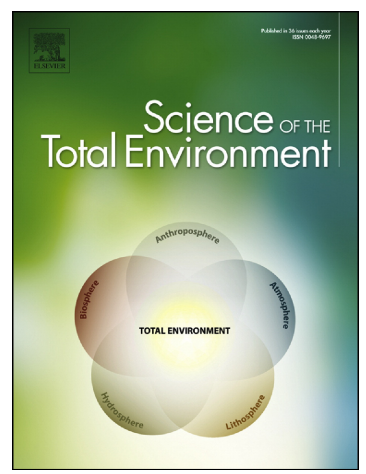

S.M. Seyedpour, P. Kirmizakis, P. Brennan, R. Doherty, T. Ricken

Optimal remediation design and simulation groundwater flow coupled to contaminant transport using genetic algorithm and radial point collocation method (RPCM)

PII: S0048-9697(19)30456-5

DOI: https://doi.org/10.1016/j.scitotenv.2019.01.409

Reference: STOTEN 30723

To appear in: Science of the Total Environment

Received date: 9 July 2018

Revised date: 30 January 2019

Accepted date:

30 January 2019

Please cite this article as: S.M. Seyedpour, P. Kirmizakis, P. Brennan, et al., Optimal remediation design and simulation groundwater flow coupled to contaminant transport using genetic algorithm and radial point collocation method (RPCM), Science of the Total Environment, https://doi.org/10.1016/j.scitotenv.2019.01.409

This is a PDF file of an unedited manuscript that has been accepted for publication. As a service to our customers we are providing this early version of the manuscript. The manuscript will undergo copyediting, typesetting, and review of the resulting proof before it is published in its final form. Please note that during the production process errors may be discovered which could affect the content, and all legal disclaimers that apply to the journal pertain. 


\title{
Optimal remediation design and simulation groundwater flow coupled to contaminant transport using genetic algorithm and radial point collocation method (RPCM)
}

\author{
S. M. Seyedpour ${ }^{\mathrm{a}, \mathrm{d}}$, P. Kirmizakis ${ }^{\mathrm{b}}$, P. Brennan ${ }^{\mathrm{c}}$, R. Doherty ${ }^{\mathrm{b}}$, T. Ricken ${ }^{\mathrm{d}, *}$ \\ ${ }^{a}$ Institute of Mechanics, Structural Analysis, and Dynamics, TU Dortmund University, 44227 Dortmund, \\ Germany \\ ${ }^{b}$ School of Natural and Built Environment, Queen's University Belfast, BT9 5AG, United Kingdom \\ ${ }^{c}$ School of Chemical Sciences, Dublin City University, Glasnevin, Dublin 9, Ireland \\ ${ }^{d}$ Institute of Mechanics, Structural Analysis and Dynamics, Faculty of Aerospace Engineering and \\ Geodesy, University of Stuttgart, 70569 Stuttgart, Germany
}

\begin{abstract}
The simulation-optimization models of groundwater and contaminant transport can be a powerful tool in the management of groundwater resources and remediation design. In this study, using Multiquadratic Radial Basis Function (MRBF) a coupled groundwater flow and reactive transport of contaminant and oxidant was developed in the framework of the Meshfree method. The parameter analysis has determined the optimum shape parameter (0.97), and the results of the model were compared with a physical sandbox model which were in good agreement. The Genetic Algorithm approach was used to find the optimum design of the remediation using permanganate as an oxidant. To find the optimum design we considered two objectives and two constraints. The results revealed that the breakthrough of contaminant to the downstream area of interest and the concentration of the contaminant in this area is reduced significantly with optimisation.
\end{abstract}

Keywords: Groundwater flow, Reactive contaminant transport, Radial basis function, Point collocation method, Genetic Algorithm

\section{Introduction}

Groundwater is a primary resource for drinking water, agriculture and industry (An et al., 2013; Zhang et al., 2017), and its contamination can have long-term negative influences on the environment causing severe disasters (Chen et al., 2017; Elimelech and Phillip, 2011). Aside from pollution issues, the water scarcity in freshwater lakes, rivers

\footnotetext{
* Corresponding author

Email addresses: seyedmorteza. seyedpouretu-dortmund.de (S. M. Seyedpour), pkirmizakis01@qub.ac.uk (P. Kirmizakis), peter.brennan234@mail.dcu.ie (P. Brennan), r.doherty@qub.ac.uk (R. Doherty), ricken@isd.uni-stuttgart.de (T. Ricken)
} 
and aquifers, namely blue water, due to droughts (EU, 2007) and greater demand because of intensive industrial and economic growth (WWAP, 2015), namely water stress, have increased the importance of proactively protecting uncontaminated groundwater sources and reactively remediating contaminated sources. Thus, the selection of a remediation technology among different remedial strategies and optimising remediation design, are challenging issues with which decision-makers currently struggle (Hadley and Newell, 2012; Stroo et al., 2012). Numerical modeling of groundwater flow and contaminant transport can play a crucial role in groundwater management (Wang and Anderson, 1982). The results of simulations can not only reveal the behaviour of contaminant migration through the porous media with respect to space and time but also can be used to optimise the remediation process. Furthermore, coupled simulationoptimization approaches for groundwater flow, contaminant fate and remediation technologies can address uncertainties in remediation design and reduce expenses (Tam and Byer, 2002; Baú and Mayer, 2007; He et al., 2009). The groundwater flow and contaminant transport, mathematically, can be expressed by differential equations considering dispersion, advection, sorption, reaction, degradation, etc (Sun and Sun, 2013; Sharma and Reddy, 2004). In general, there are two different approaches to solve these equations, analytical and numerical methods. The analytical approaches are applicable only when the boundary conditions and the geometries are simplified (Zheng and Bennett, 2002), while the numerical strategies can be applied to many sophisticated problems. There are different numerical approaches, including finite difference method (FDM) (Tatalovich et al., 2000), finite volume method (FVM) (Bertolazzi and Manzini, 2004), finite element method (FEM) (Robeck et al., 2011; Ricken et al., 2014; SCHMUCK et al., 2016; Seyedpour and Ricken, 2016), and boundary element method (BEM) (Leo and Booker, 1998) which can be used to solve the governing equation of groundwater flow and contaminant transport. Although their success in dealing with geometry complexity and heterogeneity, they encounter some difficulties in a simulation of high advection velocities and the low diffusion resulting in high Peclet number and also low dispersivities.

Recently, Meshfree methods, in addition to other numerical techniques, have become popular in groundwater modelling. In contrast to the grid or mesh-based approaches, Meshfree methods, do not suffer from shortcomings such as numerical dispersion, meshing, remeshing in FDM and FEM which often lead to substantial cost and time in the adaptive analysis, and limitation in some problems such as large deformation and the breakage of material (Liu and $\mathrm{Gu}, 2005$ ). Meshless methods include the smoothparticle hydrodynamics, kernel, moving least squares, the element-free Galerkin, partition of unity, local Petrov-Galerkin and point collocation. Each method has its own merits and disadvantages in particular problems. The solution procedure in the Meshfree methods departs from FEM in the geometry representation and shape function construction. In the Meshfree methods, instead of meshes, the geometry and its boundary are represented by nodes. Polynomial basis functions and radial basis functions (RBF) have often been used to construct shape functions to approximate the unknown field parameters in the point collocation method. RBFs can be applied to support the decisionmaking process of environmental management strategies such as the investigation of different nourishment scenarios of coastline (Bergillos et al., 2018), optimal design of wave energy converters at coastal areas (Lpez-Ruiz et al., 2018) and also groundwater 
modelling. Kumar et al. investigated a Meshfree simulation for contaminant transport through saturated porous media using thin plate spline radial basis functions to construct shape functions. The authors validated their simulation with experimental results. Their results were in good agreement with FEM simulation (Praveen Kumar and Dodagoudar, 2008). Meenal and Eldho developed a Meshfree model using multi-quadric radial basis functions based on collocation method to simulate groundwater flow in an unconfined aquifer (Meenal and Eldho, 2011). They extended their model for the two-dimensional coupled groundwater flow and transport simulation in an unconfined aquifer and verified the accuracy of their model with analytical solutions (Meenal and Eldho, 2012). Singh et al. developed the RPCM method for coupled groundwater flow and contaminant transport simulation in a confined aquifer in steady state and compared their results with experimental results (Guneshwor Singh et al., 2016). Yao et al. presented RBF mesh free description for reactive transport of dioxin as a contaminant and slow release of permanganate as an oxidant to better understand the design for large scale contaminated sites (Yao et al., 2016).

Traditional mathematical methods, used to optimize the problems in different areas of engineering practices, have lost their effectiveness as problems have become more complex; hence other optimization algorithms such as natural computing are investigated. Natural computing methods are one class of biomimicry optimisation methods such as genetic algorithm (GA), particle swarm optimisation (PSO), differential evolution and artificial bee colony are effective methods to optimise complicated environmental problems such as groundwater remediation process. Genetic Algorithm, introduced by Holland (Holland, 1992), is one of the functional natural computing methods belongs to the evolutionary computing algorithms. Genetic Algorithms, which are based on the theory of evolution, mimic natural evolution or information handling with respect to problems in other scientific areas such as environmental engineering (Sotomayor et al., 2018; Varghese et al., 2015). By utilizing genetic principles including selection, population, crossover and mutation, this method finds optimum solutions to problems, and in our study, this solution discovers the optimal number and design for oxidant resources. The genetic algorithm begins the solution process by selecting a relatively small population in which every individual represents a possible solution in the parameter space, and the efficiency of each individual is determined using objective functions. The new generation is reproduced by utilising probability rules in the combination of the concept of selection, crossover and mutation leading to decrease the survival chance of the less fit individuals. Sinha et al. developed a multiscale island injection genetic algorithm (IIGA) and tested it using a field-scale pump-and-treat design problem at the Umatilla Army Depot in Oregon, USA (Sinha and Minsker, 2007). He et al. investigated their previous works (Huang, 1992; He et al., 2008b,a) to optimise the design of field-scale pump and treat system (PAT). The authors simulated the transport of petroleum as a contaminant and assumed the porosity of the soil to be stochastic variables with normal distribution (He et al., 2009). They found that the remediation cost might increase because of the effects of uncertainty. With the aid of the knowledge of forensic observations, Tian et al. used quantum-behaved particle swarm optimization to solve an inverse advection-dispersion problem of estimating the strength of time-varying groundwater contaminant source. They concluded that the proposed method can be used efficiently to reconstruct the contaminant source history 
Fig. 1: The aquifer domain and physical setting of the model.

(Tian et al., 2011).

It is natural for decision makers to want assurance that the numerical models are valid. To validate the numerical approaches, analytical solution, real field data and a physical model such as sandbox experiment can be used. The Sandbox experiment can be used not only as an experimental method for validating simulations but also visualising, predicting (Illman et al., 2012) a solute transport.

The main objectives of this paper are to develop a model for groundwater flow and reactive transport utilising MFree RPCM and finding optimal remediation design using GA. The model provides an effective remediation design based on considered objectives and constraints. Furthermore, the shape parameter analysis has been done to determine the optimum shape parameter and the results of the model were compared with a physical sandbox model.

\section{Governing equations and boundary conditions}

\subsection{Groundwater flow}

The transient flow of groundwater through a saturated, anisotropic, inhomogeneous, porous aquifer in 2D can be written as (Bear, 1979, 2007)

$$
\frac{\partial}{\partial \mathrm{x}}\left[\mathrm{k}_{\mathrm{x}} \frac{\partial \mathrm{h}}{\partial \mathrm{x}}\right]+\frac{\partial}{\partial \mathrm{y}}\left[\mathrm{k}_{\mathrm{y}} \frac{\partial \mathrm{h}}{\partial \mathrm{y}}\right]=\mathrm{S} \frac{\partial \mathrm{h}}{\partial \mathrm{t}}+\mathrm{Q}_{\mathrm{w}}\left(\mathrm{x}-\mathrm{x}_{\mathrm{i}}\right)\left(\mathrm{y}-\mathrm{y}_{\mathrm{i}}\right)-\mathrm{q} .
$$

where $\mathrm{h}(\mathrm{x}, \mathrm{y}, \mathrm{t})$ is the piezometric head $[\mathrm{L}], \mathrm{k}_{\mathrm{x}}$ and $\mathrm{k}_{\mathrm{y}}$ are hydraulic conductivity in $\mathrm{x}$ and $\mathrm{y}$ direction $\left[\mathrm{LT}^{-1}\right], \mathrm{S}$ is the storage coefficient, $\mathrm{Q}_{\mathrm{w}}$ is the source or sink term $\left[\mathrm{L}^{3} \mathrm{~T}^{-1} \mathrm{~L}^{-2}\right]$ and $\mathrm{q}$ denotes the recharge rate $\left[\mathrm{LT}^{-1}\right]$.

Where $\Omega$ and $\partial \Omega$ are the aquifer domain and its Lipschitz continuous boundary respectively. $\partial \Omega$ comprises of $\partial \Omega=\Gamma_{\mathrm{D}} \oplus \Gamma_{\mathrm{N}}$, where $\Gamma_{\mathrm{D}}$ and $\Gamma_{\mathrm{N}}$ interpret the portions of $\Gamma$ in which Dirichlet and Neumann boundary conditions on groundwater flow and contaminant transport equations are imposed (Fig. 1) :

$$
\begin{array}{ll}
\mathrm{h}(\mathrm{x}, \mathrm{y}, 0)=\mathrm{h}_{0}(\mathrm{x}, \mathrm{y}), & (\mathrm{x}, \mathrm{y}) \in \Omega . \\
\mathrm{h}(\mathrm{x}, \mathrm{y}, \mathrm{t})=\mathrm{h}_{1}(\mathrm{x}, \mathrm{y}), & (\mathrm{x}, \mathrm{y}) \in \Gamma_{\mathrm{D}} . \\
\mathrm{k}_{\mathrm{y}} \frac{\partial \mathrm{h}}{\partial \mathrm{y}}=0, & (\mathrm{x}, \mathrm{y}) \in \Gamma_{N} .
\end{array}
$$

\subsection{Reactive transport}

Reactive transport of the contaminant and oxidant in groundwater is given by the following coupled advection-dispersion equations (Freeze and Cherry, 1979; Wang and Anderson, 1982): 


$$
\begin{aligned}
\mathrm{R} \frac{\mathrm{n}^{\mathrm{F}}}{\mathrm{n}^{\mathrm{S}}} \frac{\partial \mathrm{C}^{1}}{\partial \mathrm{t}} & =\frac{\partial}{\partial \mathrm{x}}\left[\mathrm{D}_{\mathrm{xx}} \frac{\partial \mathrm{C}^{1}}{\partial \mathrm{x}}\right]+\frac{\partial}{\partial \mathrm{y}}\left[\mathrm{D}_{\mathrm{yy}} \frac{\partial \mathrm{C}^{1}}{\partial \mathrm{y}}\right]-\frac{\partial}{\partial \mathrm{x}}\left[v_{x} \mathrm{C}^{1}\right] \\
& -\frac{\partial}{\partial \mathrm{y}}\left[v_{y} \mathrm{C}^{1}\right]-\mathrm{KC}^{1} \mathrm{C}^{2} . \\
\mathrm{R} \frac{\mathrm{n}^{\mathrm{F}}}{\mathrm{n}^{\mathrm{S}}} \frac{\partial \mathrm{C}^{2}}{\partial \mathrm{t}} & =\frac{\partial}{\partial \mathrm{x}}\left[\mathrm{D}_{\mathrm{xx}} \frac{\partial \mathrm{C}^{2}}{\partial \mathrm{x}}\right]+\frac{\partial}{\partial \mathrm{y}}\left[\mathrm{D}_{\mathrm{yy}} \frac{\partial \mathrm{C}^{2}}{\partial \mathrm{y}}\right]-\frac{\partial}{\partial \mathrm{x}}\left[v_{x} \mathrm{C}^{2}\right] \\
& -\frac{\partial}{\partial \mathrm{y}}\left[v_{y} \mathrm{C}^{2}\right]-\mathrm{KC}^{1} \mathrm{C}^{2}+\mathrm{F}_{\text {release }} \delta\left(\mathrm{x}-\mathrm{x}_{\mathrm{i}}\right)\left(\mathrm{y}-\mathrm{y}_{\mathrm{i}}\right) .
\end{aligned}
$$

where $\mathrm{R}$ is retardation factor and describes sorption, $\mathrm{n}^{\mathrm{F}}$ and $\mathrm{n}^{\mathrm{S}}$ are volume fractions of groundwater and soil respectively, and their fraction $\frac{n^{F}}{n^{S}}$ denotes the porosity of the aquifer, $\mathrm{D}_{\mathrm{x}}$ and $\mathrm{D}_{\mathrm{y}}$ are components of dispersion coefficient tensor in $\mathrm{x}$ and $\mathrm{y}$ directions respectively $\left[\mathrm{L}^{2} \mathrm{~T}^{-1}\right] . \mathrm{C}^{1}$ and $\mathrm{C}^{2}$ are concentration of 1,4-Dioxacyclohexane $\left(\mathrm{C}_{4} \mathrm{H}_{8} \mathrm{O}_{2}\right)$ as a contaminant and permanganate as an oxidant respectively $\left[\mathrm{ML}^{-3}\right], \mathrm{k}$ is second order reaction constant $\left[\mathrm{T}^{-1}\right]$ and $\mathrm{F}_{\text {Release }}$ is the release function of permanganate (Wolf, 2013). $v_{x}$ and $v_{y}$ are seepage velocity vectors in $\mathrm{x}$ and y directions respectively $\left[\mathrm{LT}^{-1}\right]$ evaluated from the solutions of the flow equations using the following relations (Bear, 1979, 2007):

$$
\mathrm{v}_{\mathrm{x}}=-\mathrm{k}_{\mathrm{x}} \frac{\partial \mathrm{h}}{\partial \mathrm{x}} ; \mathrm{v}_{\mathrm{y}}=-\mathrm{k}_{\mathrm{y}} \frac{\partial \mathrm{h}}{\partial \mathrm{y}} .
$$

where $\mathrm{k}_{\mathrm{x}}$ and $\mathrm{k}_{\mathrm{y}}$ are the hydraulic conductivities in $\mathrm{x}$ and $\mathrm{y}$ directions respectively. The components of the dispersion coefficient tensor, $\mathbf{D}=\mathbf{D}(\mathrm{x})$, are evaluated using the following relations:

$$
\mathrm{D}_{\mathrm{xx}}=\frac{\alpha_{\mathrm{L} \mathrm{x}_{\mathrm{x}}}{ }^{2}+\alpha_{\mathrm{T} \mathrm{v}_{\mathrm{y}}}^{2}}{\sqrt{\mathrm{v}_{\mathrm{x}}^{2}+\mathrm{v}_{\mathrm{y}}^{2}}}+\mathrm{D}^{*} ; \mathrm{D}_{\mathrm{yy}}=\frac{\alpha_{\mathrm{L}} \mathrm{v}_{\mathrm{y}}^{2}+\alpha_{\mathrm{T}} \mathrm{v}_{\mathrm{x}}^{2}}{\sqrt{\mathrm{v}_{\mathrm{x}}^{2}+\mathrm{v}_{\mathrm{y}}^{2}}}+\mathrm{D}^{*} .
$$

where $\alpha_{L}$ and $\alpha_{T}$ are longitudinal and transverse dispersivity and $\mathrm{D}^{*}$ is the effective molecular diffusion coefficient. $v_{x}$ and $v_{y}$ in Eqs. (7) and (8) are evaluated from the flow equation and these two equations couple the groundwater flow and reactive transport.

For transient analysis of reactive transport, the following initial and boundary conditions are specified:

$$
\begin{aligned}
& \mathrm{C}^{1}(\mathrm{x}, \mathrm{y}, 0)=0 \quad ; \quad \mathrm{C}^{2}(\mathrm{x}, \mathrm{y}, 0)=0, \quad(\mathrm{x}, \mathrm{y}) \in \Omega . \\
& \left.\mathrm{C}^{1}(4, \mathrm{y}, \mathrm{t})\right|_{1<\mathrm{y}<3}=\hat{\mathrm{C}}^{1} \text {. } \\
& \mathrm{C}^{2}(\mathrm{x}, \mathrm{y}, \mathrm{t})=\left\{\begin{array}{l}
\mathrm{f}(\mathrm{t})_{\text {release }} \\
0
\end{array} \quad(\mathrm{x}, \mathrm{y})\right. \text { in Oxidan source } \\
& \frac{\partial \mathrm{C}^{1}}{\partial \mathrm{y}}=0 ; \frac{\partial \mathrm{C}^{2}}{\partial \mathrm{y}}=0, \quad(\mathrm{x}, \mathrm{y}) \in \Gamma_{N} .
\end{aligned}
$$


Fig. 2: Different local support domains used in Meshfree methods.

\section{RPCM formulation}

\subsection{Radial basis function interpolation}

In the Meshfree method, the problem domain and its boundaries are represented by a set of nodes, namely field nodes, scattered within the problem domain and its boundaries. The initial step to solve PDEs through the Meshfree method is the approximation of unknown field variables using trial or shape function. To approximate the function values at node $\mathrm{x}$, a set of neighbourhood nodes called local support domains are used to construct shape functions but the shape functions outside of the local support domains are regarded as zero. In contrast to the finite element method in which the shape function is the same for the entire elements, in the Meshfree method, the shape functions and the local support domains can change for a different point of interest. Fig. 2 illustrates various types of local support domains used in the Meshfree method.

Among these support domains, circular and rectangular support domains are more common. To construct Meshfree shape functions used in the point interpolation method, two different types of basis functions, namely Radial basis function (JG Wang, 2002) and polynomial basis (GR, 1999) have been investigated. To approximate the piezometric head, the following linear combination of the radial and polynomial basis functions can be used (Liu and Gu, 2005):

$$
\mathrm{h}(\mathbf{x})=\sum_{\mathrm{i}=1}^{\mathrm{n}} \mathrm{a}_{\mathrm{i}} \mathrm{R}_{\mathrm{i}}(\mathbf{x})+\sum_{\mathrm{j}=1}^{\mathrm{n}} \mathrm{P}_{\mathrm{i}}\left(\mathrm{xb}_{\mathrm{i}}\right)=\mathbf{R}^{\mathrm{T}}(\mathbf{x}) \mathbf{a}+\mathbf{P}^{\mathrm{T}}(\mathbf{x}) \mathbf{b} .
$$

where $\mathrm{R}(\mathbf{x})$ and $\mathrm{P}(\mathbf{x})$ denote radial basis and polynomial basis functions respectively, $n$ is the number of RBFs, $m$ is the number of polynomials where $m$ is usually smaller than $\mathrm{n}$ and when $\mathrm{m}=0$, the interpolation is dominated only by pure RBFs. Coefficients $\mathrm{a}_{\mathrm{i}}$ and $\mathrm{b}_{\mathrm{i}}$ are constants which can be determined by enforcing the interpolation function passing through all nodes within the support domain.

There are four common types of RBFs whose characteristics have been investigated in many studies (Kansa, 1990; Schaback and Wendland, 2000; Hardy, 1971) including the multi-quadrics (MQ) function, the exponential or Gaussian (Exp) function, the thin plate spline (TPS) function, and the Logarithmic radial basis function. In all RBFs, the only variable is the distance between the point of interest $\mathbf{x}$ and a node located at $\mathbf{x}_{\mathbf{i}}$ that can be expressed as:

$$
\mathrm{r}=\sqrt{\left(\mathrm{x}-\mathrm{x}_{\mathrm{i}}\right)^{2}+\left(\mathrm{y}-\mathrm{y}_{\mathrm{i}}\right)^{2}}, \quad \text { for } 2 \mathrm{D} \text { Problems. }
$$

In our study, among different radial basis functions, we have chosen multi-quadrics which is defined as below:

$$
\mathrm{R}_{\mathrm{i}}(\mathrm{x}, \mathrm{y})=\left(\mathrm{r}_{\mathrm{i}}^{2}+\left(\alpha_{\mathrm{c}} \mathrm{d}_{\mathrm{c}}\right)^{2}\right)^{\mathrm{q}} .
$$


where $\alpha_{c}, \mathrm{~d}_{\mathrm{c}}$ and $\mathrm{q}$ are the shape parameters. $\alpha_{c}$ controls the size of support domain, and $d_{c}$ is the average nodal spacing in the support domain near the point of interest, and it is defined using the following equation:

$$
\mathrm{d}_{\mathrm{c}}=\frac{\sqrt{\mathrm{A}_{\mathrm{s}}}}{\sqrt{\mathrm{n}_{\mathrm{A}_{\mathrm{s}}}}-1} .
$$

where $A_{S}$ is the area of the estimated support domain and $n_{A_{s}}$ is the number of nodes embraced by the estimated area of $\mathrm{A}_{\mathrm{s}}$. Among different support domains used to construct shape functions, we have chosen the rectangular domain which is easy to build and implement. The dimension of the rectangular support domain is determined by the following relations:

$$
\begin{aligned}
& \mathrm{d}_{\mathrm{sx}}=\alpha_{\mathrm{Cx}} \mathrm{d}_{\mathrm{cx}} . \\
& \mathrm{d}_{\mathrm{sy}}=\alpha_{\mathrm{Cy}} \mathrm{d}_{\mathrm{cy}} .
\end{aligned}
$$

where $d_{c x}$ and $d_{c y}$ are nodal spacing in $x$ and $y$ directions (Fig. 2). Shape parameters play a crucial role in the accuracy of numerical solutions while RBFs are used in Meshfree methods. Although there is no established method to choose the optimum value for shape parameter, some studies have been conducted to find the optimum shape parameter for specific types of problems (Rippa, 1999; Wang and Liu, 2002; Wright, 2003). The unknown coefficients $a_{i}$ and $b_{j}$ in Eq. (13) are established by enforcing the interpolation function passing through all $n$ scattered nodes within the support domain leading to $n$ algebraic equations expressed in matrix form as:

$$
\mathbf{h}^{\mathrm{T}}=\mathbf{R}_{\mathbf{Q}} \mathbf{a}+\mathbf{P}_{\mathbf{m}} \mathbf{b}
$$

The moment matrices corresponding to the radial basis function $\mathbf{R}_{\mathbf{Q}}$ and the polynomial basis function $\mathbf{P}_{\mathbf{Q}}$ are expressed by the following relations:

$$
\begin{gathered}
\mathbf{R}_{\mathbf{Q}}=\left[\begin{array}{cccc}
\mathrm{R}_{1}\left(\mathrm{x}_{1}, \mathrm{y}_{1}\right) & \mathrm{R}_{2}\left(\mathrm{x}_{1}, \mathrm{y}_{1}\right) & \cdot & \mathrm{R}_{\mathrm{n}}\left(\mathrm{x}_{1}, \mathrm{y}_{1}\right) \\
\mathrm{R}_{1}\left(\mathrm{x}_{2}, \mathrm{y}_{2}\right) & \mathrm{R}_{2}\left(\mathrm{x}_{2}, \mathrm{y}_{2}\right) & \cdot & \mathrm{R}_{\mathrm{n}}\left(\mathrm{x}_{2}, \mathrm{y}_{2}\right) \\
\cdot & \cdot & \cdot & \cdot \\
\mathrm{R}_{1}\left(\mathrm{x}_{\mathrm{n}}, \mathrm{y}_{\mathrm{n}}\right) & \mathrm{R}_{2}\left(\mathrm{x}_{\mathrm{n}}, \mathrm{y}_{\mathrm{n}}\right) & \cdot & \mathrm{R}_{\mathrm{n}}\left(\mathrm{x}_{\mathrm{n}}, \mathrm{y}_{\mathrm{n}}\right)
\end{array}\right]_{n \times n}, \\
\mathbf{P}_{\mathbf{m}}=\left[\begin{array}{cccc}
\mathrm{P}_{1}\left(\mathrm{x}_{1}, \mathrm{y}_{1}\right) & \mathrm{P}_{2}\left(\mathrm{x}_{1}, \mathrm{y}_{1}\right) & \cdot & \mathrm{P}_{\mathrm{m}}\left(\mathrm{x}_{1}, \mathrm{y}_{1}\right) \\
\mathrm{P}_{1}\left(\mathrm{x}_{2}, \mathrm{y}_{2}\right) & \mathrm{P}_{2}\left(\mathrm{x}_{2}, \mathrm{y}_{2}\right) & \cdot & \mathrm{P}_{\mathrm{m}}\left(\mathrm{x}_{2}, \mathrm{y}_{2}\right) \\
\cdot & \cdot & \cdot & \cdot \\
\mathrm{P}_{1}\left(\mathrm{x}_{\mathrm{n}}, \mathrm{y}_{\mathrm{n}}\right) & \mathrm{P}_{2}\left(\mathrm{x}_{\mathrm{n}}, \mathrm{y}_{\mathrm{n}}\right) & \cdot & \mathrm{P}_{\mathrm{m}}\left(\mathrm{x}_{\mathrm{n}}, \mathrm{y}_{\mathrm{n}}\right)
\end{array}\right]_{n \times m}
\end{gathered} .
$$

There is $n+m$ unknowns in Eq. (18) and in order to determine all the unknowns, the following $\mathrm{m}$ additional equations need to be added to the system equations:

$$
\sum_{i=1}^{n} \mathrm{p}_{\mathrm{j}}\left(\mathbf{x}_{\mathbf{i}}\right) \mathrm{a}_{\mathrm{i}}=\mathrm{P}_{\mathrm{m}}^{\mathrm{T}} \mathbf{a}=0, \quad \mathrm{j}=1,2, \ldots, \mathrm{m} .
$$

Eq. (17) and Eq. (20) together can be written as below:

$$
\left[\begin{array}{cc}
\mathbf{R}_{\mathbf{Q}} & \mathbf{P}_{\mathbf{m}} \\
\mathbf{P}_{\mathbf{m}}^{\mathbf{T}} & \mathbf{0}
\end{array}\right]\left\{\begin{array}{l}
\mathbf{a} \\
\mathbf{b}
\end{array}\right\}=\left\{\begin{array}{c}
\mathbf{h}^{\mathbf{T}} \\
0
\end{array}\right\}
$$


substituting unknown coefficients into Eq. (13), the interpolation can be written as:

$$
\mathbf{h}(\mathbf{x})=\boldsymbol{\Xi}^{\mathbf{T}}(\mathbf{x}) \mathbf{h}_{\mathbf{s}}
$$

where $\boldsymbol{\Xi}(\mathbf{x})$ are the shape functions and expressed as:

$$
\Xi(\mathrm{x})=\left\{\Xi_{1}(\mathrm{x}, \mathrm{y}) \Xi_{2}(\mathrm{x}, \mathrm{y}) \ldots \Xi_{n}(\mathrm{x}, \mathrm{y})\right\}
$$

and $\mathbf{h}_{\mathbf{s}}=\left\{\mathrm{h}_{1} \mathrm{~h}_{2} \ldots \mathrm{h}_{\mathrm{n}}\right\}$ is the nodal head values vector at the support domain nodes. The first and second derivatives of piezometric head in $\mathrm{x}$ and $\mathrm{y}$ directions at any point can be expressed by the following equations:

$$
\begin{array}{ll}
\frac{\partial \mathbf{h}_{\mathbf{l}}}{\partial \mathrm{x}}=\frac{\partial \boldsymbol{\Xi}^{\mathbf{T}}}{\partial \mathrm{x}} \mathbf{h}_{\mathbf{s}}=\sum_{i=1}^{n} \frac{\partial \Xi_{i}}{\partial \mathrm{x}} \mathrm{h}_{\mathrm{i}} \quad ; \quad \frac{\partial^{2} \mathbf{h}_{\mathbf{l}}}{\partial \mathrm{x}^{2}}=\frac{\partial^{2} \boldsymbol{\Xi}^{\mathbf{T}}}{\partial \mathrm{x}^{2}} \mathbf{h}_{\mathbf{s}}=\sum_{\mathrm{i}=1}^{\mathrm{n}} \frac{\partial^{2} \Xi_{\mathrm{i}}}{\partial \mathrm{x}^{2}} \mathrm{~h}_{\mathrm{i}} . \\
\frac{\partial \mathbf{h}_{\mathbf{l}}}{\partial \mathrm{y}}=\frac{\partial \boldsymbol{\Xi}^{\mathbf{T}}}{\partial \mathrm{y}} \mathbf{h}_{\mathbf{s}}=\sum_{i=1}^{n} \frac{\partial \Xi_{i}}{\partial \mathrm{y}} \mathrm{h}_{\mathrm{i}} \quad ; \quad \frac{\partial^{2} \mathbf{h}_{\mathbf{l}}}{\partial \mathrm{y}^{2}}=\frac{\partial^{2} \boldsymbol{\Xi}^{\mathbf{T}}}{\partial \mathrm{y}^{2}} \mathbf{h}_{\mathbf{s}}=\sum_{\mathrm{i}=1}^{\mathrm{n}} \frac{\partial^{2} \Xi_{\mathrm{i}}}{\partial \mathrm{y}^{2}} \mathrm{~h}_{\mathrm{i}} .
\end{array}
$$

\subsection{Discretisation of governing equations}

\subsubsection{Time discretisation}

The time discretisation has been executed using the widely known Crank-Nicholson time stepping method in which the time derivative is replaced with a simple forward difference while the solution is replaced with a weighted value of the previous time-step solution, and the current solution expressed by the following equations:

$$
\begin{gathered}
\frac{\partial \mathrm{h}}{\partial \mathrm{t}}=\frac{\mathrm{h}^{t+\Delta \mathrm{t}}-\mathrm{h}^{t}}{\Delta \mathrm{t}} \\
\mathrm{h}=\frac{\mathrm{h}^{t+\Delta \mathrm{t}}+\mathrm{h}^{t}}{2}
\end{gathered}
$$

\subsubsection{RPCM approximation}

By the collocation of groundwater flow equation at all internal nodes using Eq. (22), the following discretised form of the piezometric head can be written:

$$
\mathrm{k}\left(\mathbf{x}_{\mathrm{r}}\right)\left[\frac{\partial^{2} \boldsymbol{\Xi}^{\mathrm{T}}}{\partial \mathrm{x}^{2}}+\frac{\partial^{2} \boldsymbol{\Xi}^{\mathrm{T}}}{\partial \mathrm{y}^{2}}\right] \mathbf{h}_{\mathrm{s}}(\mathrm{t})=\mathrm{S}\left(\mathbf{x}_{\mathrm{r}}\right)\left(\frac{\partial \mathrm{h}}{\partial \mathrm{t}}\right)+\mathrm{Q}_{\mathrm{w}} \delta\left(\mathbf{x}_{\mathrm{r}}-\mathbf{x}_{\mathrm{i}}\right)-\mathrm{q}\left(\mathbf{x}_{\mathrm{r}}\right)
$$

Substituting Eq.(25), the following equation is achieved:

$$
\begin{aligned}
& \frac{1}{2} \mathrm{k}\left(\mathbf{x}_{\mathrm{r}}\right)\left[\frac{\partial^{2} \boldsymbol{\Xi}^{\mathrm{T}}}{\partial \mathrm{x}^{2}}+\frac{\partial^{2} \boldsymbol{\Xi}^{\mathrm{T}}}{\partial \mathrm{y}^{2}}\right] \mathbf{h}_{\mathrm{s}}^{\mathrm{t}+\Delta \mathrm{t}}+\frac{1}{2} \mathrm{k}\left(\mathbf{x}_{\mathrm{r}}\right)\left[\frac{\partial^{2} \boldsymbol{\Xi}^{\mathrm{T}}}{\partial \mathrm{x}^{2}}+\frac{\partial^{2} \boldsymbol{\Xi}^{\mathrm{T}}}{\partial \mathrm{y}^{2}}\right] \mathbf{h}_{\mathrm{s}}^{\mathrm{t}} \\
& =\mathrm{S}_{\mathrm{r}}\left(\frac{\boldsymbol{\Xi}^{\mathrm{T}} \mathbf{h}_{\mathrm{s}}^{\mathrm{t}+\Delta \mathrm{t}}-\mathrm{h}_{\mathrm{r}}^{\mathrm{t}}}{\Delta \mathrm{t}}\right)+\mathrm{Q}_{\mathrm{w}} \delta\left(\mathbf{x}_{\mathrm{r}}-\mathbf{x}_{\mathbf{i}}\right)-\mathrm{q}_{\mathrm{r}} .
\end{aligned}
$$


A similar approach is performed to discretise reactive transport equations, and the equations below are achieved:

$$
\begin{aligned}
& \mathrm{C}^{\mathrm{j}}(\mathrm{x}, \mathrm{t})=\sum_{\mathrm{i}=1}^{\mathrm{n}} \Xi_{\mathrm{i}}(\mathrm{x}) \mathrm{C}_{\mathrm{i}}^{\mathrm{j}}(\mathrm{t})=\boldsymbol{\Xi}^{\mathrm{T}} \mathbf{C}_{\mathrm{s}}^{\mathrm{j}}, \quad \mathrm{j}=1,2 . \\
& \mathrm{R} \frac{\mathrm{n}^{\mathrm{f}}}{\mathrm{n}^{\mathrm{s}}} \frac{\boldsymbol{\Xi}^{\mathrm{T}} \mathbf{C}_{\mathbf{s}}^{\mathbf{1}}-\mathrm{C}_{\mathrm{r}}^{1 \mathrm{t}}}{\Delta \mathrm{t}}=\frac{1}{2}\left[\mathrm{D}_{\mathrm{xx}_{\mathrm{r}}} \frac{\partial^{2} \boldsymbol{\Xi}^{\mathrm{T}}}{\partial \mathrm{x}^{2}}+\mathrm{D}_{\mathrm{yy}_{\mathrm{r}}} \frac{\partial^{2} \boldsymbol{\Xi}^{\mathrm{T}}}{\partial \mathrm{y}^{2}}\right] \mathbf{C}_{\mathrm{s}}^{1 \mathrm{t}+\Delta \mathrm{t}}+ \\
& \frac{1}{2}\left[\mathrm{D}_{\mathrm{xx}_{\mathrm{r}}} \frac{\partial^{2} \boldsymbol{\Xi}^{\mathrm{T}}}{\partial \mathrm{x}^{2}}+\mathrm{D}_{\mathrm{yy}_{\mathrm{r}}} \frac{\partial^{2} \boldsymbol{\Xi}^{\mathrm{T}}}{\partial \mathrm{y}^{2}}\right] \mathbf{C}_{\mathrm{s}}^{1 \mathrm{t}}-\frac{1}{2}\left[\mathrm{v}_{\mathrm{x}_{\mathrm{r}}} \frac{\partial \boldsymbol{\Xi}^{\mathrm{T}}}{\partial \mathrm{x}}+\mathrm{v}_{\mathrm{yr}_{\mathrm{r}}} \frac{\partial \boldsymbol{\Xi}^{\mathrm{T}}}{\partial \mathrm{y}}\right] \mathbf{C}_{\mathrm{s}}^{1 \mathrm{t}+\Delta \mathrm{t}}- \\
& \frac{1}{2}\left[\mathrm{v}_{\mathrm{x}_{\mathrm{r}}} \frac{\partial \boldsymbol{\Xi}^{\mathrm{T}}}{\partial \mathrm{x}}+\mathrm{v}_{\mathrm{y}_{\mathrm{r}}} \frac{\partial \boldsymbol{\Xi}^{\mathrm{T}}}{\partial \mathrm{y}}\right] \mathbf{C}_{\mathrm{s}}^{1 \mathrm{t}}--\mathrm{K} \boldsymbol{\Xi}^{\mathrm{T}} \mathrm{C}^{1 \mathrm{t}} \boldsymbol{\Xi}^{\mathrm{T}} \mathrm{C}^{2 \mathrm{t}} \\
& \mathrm{R} \frac{\mathrm{n}^{\mathrm{f}}}{\mathrm{n}^{\mathrm{s}}} \frac{\boldsymbol{\Xi}^{\mathrm{T}} \mathbf{C}_{\mathbf{s}}^{\mathbf{2}}-\mathrm{C}_{\mathrm{r}}^{2 \mathrm{t}}}{\Delta \mathrm{t}}=\frac{1}{2}\left[\mathrm{D}_{\mathrm{xx}_{\mathrm{r}}} \frac{\partial^{2} \boldsymbol{\Xi}^{\mathrm{T}}}{\partial \mathrm{x}^{2}}+\mathrm{D}_{\mathrm{yy}_{\mathrm{r}}} \frac{\partial^{2} \boldsymbol{\Xi}^{\mathrm{T}}}{\partial \mathrm{y}^{2}}\right] \mathbf{C}_{\mathrm{s}}^{2 \mathrm{t}+\Delta \mathrm{t}+} \\
& \frac{1}{2}\left[\mathrm{D}_{\mathrm{xx}_{\mathrm{r}}} \frac{\partial^{2} \boldsymbol{\Xi}^{\mathrm{T}}}{\partial \mathrm{x}^{2}}+\mathrm{D}_{\mathrm{yy}_{\mathrm{r}}} \frac{\partial^{2} \boldsymbol{\Xi}^{\mathrm{T}}}{\partial \mathrm{y}^{2}}\right] \mathbf{C}_{\mathrm{s}}^{2 \mathrm{t}} \frac{1}{2}\left[\mathrm{v}_{\mathrm{x}_{\mathrm{r}}} \frac{\partial \boldsymbol{\Xi}^{\mathrm{T}}}{\partial \mathrm{x}}+\mathrm{v}_{\mathrm{y}_{\mathrm{r}}} \frac{\partial \boldsymbol{\Xi}^{\mathrm{T}}}{\partial \mathrm{y}}\right] \mathbf{C}_{\mathrm{s}}^{2 \mathrm{t}+\Delta \mathrm{t}}- \\
& \frac{1}{2}\left[\mathrm{v}_{\mathbf{x}_{\mathrm{r}}} \frac{\partial \boldsymbol{\Xi}^{\mathrm{T}}}{\partial \mathrm{x}}+\mathrm{v}_{\mathrm{y}_{\mathrm{r}}} \frac{\partial \boldsymbol{\Xi}^{\mathrm{T}}}{\partial \mathrm{y}}\right] \mathbf{C}_{\mathrm{s}}^{2 \mathrm{t}}-\mathbf{K} \boldsymbol{\Xi}^{\mathrm{T}} \mathbf{C}^{1 \mathrm{t}} \boldsymbol{\Xi}^{\mathrm{T}} \mathrm{C}^{2 \mathrm{t}}+\mathrm{F}_{\text {release }}(\mathrm{t}) \delta\left(\mathbf{x}_{\mathrm{r}}-\mathbf{x}_{\mathbf{i}}\right) \text {. }
\end{aligned}
$$

where the seepage velocity, $\mathrm{v}_{\mathrm{x}}$ and $\mathrm{v}_{\mathrm{y}}$, and dispersion coefficients are determined by substituting Eq. (24) in Eq. (7) and Eq. (8) resulting in the following equations:

$$
\begin{gathered}
\mathrm{v}_{\mathrm{x}_{\mathrm{r}}}=-\mathrm{k}_{\mathrm{x}_{\mathrm{r}}} \frac{\partial \boldsymbol{\Xi}^{\mathrm{T}}}{\partial \mathrm{x}} \mathbf{h}_{\mathrm{s}} ; \mathrm{v}_{\mathrm{y}_{\mathrm{r}}}=-\mathrm{k}_{\mathrm{x}_{\mathrm{r}}} \frac{\partial \boldsymbol{\Xi}^{\mathrm{T}}}{\partial \mathrm{y}} \mathbf{h}_{\mathrm{s}} . \\
\mathrm{D}_{\mathrm{xx}_{\mathrm{r}}}=\frac{\left(-\alpha_{\mathrm{L}} \mathrm{k}_{\mathrm{x}_{\mathrm{r}}} \frac{\partial \boldsymbol{\Xi}^{\mathrm{T}}}{\partial \mathrm{x}} \mathbf{h}_{\mathrm{s}}\right)^{2}+\left(-\alpha_{\mathrm{T}} \mathrm{k}_{\mathrm{y}_{\mathrm{r}}} \frac{\partial \boldsymbol{\Xi}^{\mathrm{T}}}{\partial \mathrm{y}} \mathbf{h}_{\mathrm{s}}\right)^{2}}{\sqrt{\left(-\mathrm{k}_{\mathrm{x}_{\mathrm{r}}} \frac{\partial \boldsymbol{\Xi}^{\mathrm{T}}}{\partial \mathrm{x}} \mathbf{h}_{\mathrm{s}}\right)^{2}+\left(-\mathrm{k}_{\mathrm{x}_{\mathrm{r}}} \frac{\partial \boldsymbol{\Xi}^{\mathrm{T}}}{\partial \mathrm{y}} \mathbf{h}_{\mathrm{s}}\right)^{2}}+\mathrm{D}^{*}} \\
\mathrm{D}_{\mathrm{yy}_{\mathrm{r}}}=\frac{\left(-\alpha_{\mathrm{T}} \mathrm{k}_{\mathrm{x}_{\mathrm{r}}} \frac{\partial \boldsymbol{\Xi}^{\mathrm{T}}}{\partial \mathrm{x}} \mathbf{h}_{\mathrm{s}}\right)^{2}+\left(-\alpha_{\mathrm{L}} \mathrm{k}_{\mathrm{y}_{\mathrm{r}}} \frac{\partial \boldsymbol{\Xi}^{\mathrm{T}}}{\partial \mathrm{y}} \mathbf{h}_{\mathrm{s}}\right)^{2}}{\sqrt{\left(-\mathrm{k}_{\mathrm{x}_{\mathrm{r}}} \frac{\partial \boldsymbol{\Xi}^{\mathrm{T}}}{\partial \mathrm{x}} \mathbf{h}_{\mathrm{s}}\right)^{2}+\left(-\mathrm{k}_{\mathrm{x}_{\mathrm{r}}} \frac{\partial \boldsymbol{\Xi}^{\mathrm{T}}}{\partial \mathrm{y}} \mathbf{h}_{\mathrm{s}}\right)^{2}}+\mathrm{D}^{*}}
\end{gathered}
$$

The accuracy and stability of the solution using the collocation method depend on imposing and implementing the boundary conditions at boundary nodes, in particular, Neumann boundary conditions. There are different methods to impose derivatives 
boundary conditions which have been discussed in studies (Liu and $\mathrm{Gu}, 2005$ ). In this study, we have used the direct collocation method to implement the Neumann boundary condition. The following examples denote the implementation of the Dirichlet and Neuman boundary condition on groundwater flow equations.

$$
\begin{aligned}
& \mathrm{h}\left(\mathrm{x}_{1}, \mathrm{y}_{1}\right)=\mathrm{h}_{0}=\boldsymbol{\Xi}^{\mathrm{T}} \mathbf{h}_{\mathrm{s}}, \\
& \boldsymbol{\Xi}^{\mathrm{T}}=\left\{\Xi_{1} \Xi_{2} \ldots \Xi_{n}\right\} . \\
& \left.\mathrm{k}_{\mathrm{y}} \frac{\partial \mathrm{h}}{\partial \mathrm{y}}\right|_{\left(\mathrm{x}_{\mathrm{n}}, \mathrm{y}_{\mathrm{n}}\right)}=0=\mathrm{k}_{\mathrm{y}_{\mathrm{r}}} \frac{\partial \boldsymbol{\Xi}^{\mathrm{T}}}{\partial \mathrm{y}} \mathbf{h}_{\mathrm{s}}, \\
& \frac{\partial \boldsymbol{\Xi}^{\mathrm{T}}}{\partial \mathrm{y}}=\left\{\frac{\partial \Xi_{1}}{\partial \mathrm{y}} \frac{\partial \Xi_{2}}{\partial \mathrm{y}} \ldots \frac{\partial \Xi_{\mathrm{n}}}{\partial \mathrm{y}}\right\} .
\end{aligned}
$$

\section{Optimal shape parameter and model verification}

To evaluate the performance of our simulation and find the optimum shape parameter, based on the introduced RPCM formulations, a coupled flow and reactive transport model was developed in MATLAB and the results are verified with two-dimensional contaminant transport benchmark equation. Furthermore, the results of the verified model are compared with the sandbox experiments results.

\subsection{Optimal shape parameters}

The following advection-diffusion transport equation with first-order decay rate constant is considered to find the optimum shape parameter

$$
\begin{gathered}
\frac{\partial \mathrm{C}}{\partial \mathrm{t}}+\frac{\rho \mathrm{b}}{\theta} \frac{\partial \mathrm{S}}{\partial \mathrm{t}}=\mathrm{D}_{\mathrm{x}} \frac{\partial^{2} \mathrm{C}}{\partial \mathrm{x}^{2}}-\mathrm{v} \frac{\partial \mathrm{C}}{\partial \mathrm{x}}+\mathrm{D}_{\mathrm{y}} \frac{\partial^{2} \mathrm{C}}{\partial \mathrm{y}^{2}}-\lambda \mathrm{C} \\
\frac{\partial \mathrm{S}}{\partial \mathrm{t}}=\alpha\left(\mathrm{K}_{\mathrm{d}} \mathrm{C}-\mathrm{S}\right)
\end{gathered}
$$

where $\mathrm{C}$ is the contaminant concentration $\left[\mathrm{ML}^{3}\right], \rho_{b}$ is the Bulk density of soil $\left[\mathrm{ML}^{3}\right]$, $\theta$ is soil porosity, $\mathrm{S}$ is Sorbed concentration $\left[\mathrm{MM}^{-1}\right], \mathrm{D}_{\mathrm{x}}$ and $\mathrm{D}_{\mathrm{y}}$ are diffusion coefficients in $\mathrm{x}$ and $\mathrm{y}$ directions $\left[\mathrm{L}^{2} \mathrm{~T}^{-1}\right], \lambda$ is first-order decay rate constant $\left[\mathrm{T}^{-1}\right], \alpha$ is first-order decay rate constant $\left[\mathrm{T}^{-1}\right]$ and $\mathrm{K}_{\mathrm{d}}$ is sorption distribution coefficient. The initial and boundary conditions are (Fig. S.1),

$$
\begin{aligned}
& \mathrm{C}(\mathrm{x}, \mathrm{y}, 0)=0 \quad ; \quad \mathrm{S}(\mathrm{x}, \mathrm{y}, 0)=0, \quad(\mathrm{x}, \mathrm{y}) \in \Omega \\
& \mathrm{C}(0, \mathrm{y}, \mathrm{t})=\left\{\begin{array}{cc}
\mathrm{C}_{0} \mathrm{H}\left(\mathrm{t}_{\mathrm{s}}-\mathrm{t}\right) & \mathrm{y}_{\mathrm{b}} \leqslant \mathrm{y} \leqslant \mathrm{y}_{\mathrm{t}} \\
0 & (\mathrm{x}, \mathrm{y}) \in \Gamma_{N} .
\end{array}\right. \\
& \frac{\partial \mathrm{C}}{\partial \mathrm{x}}=0 ; \frac{\partial \mathrm{C}}{\partial \mathrm{y}}=0
\end{aligned}
$$


The analytical solution to this problem in laplace domain were given by (Goltz and Huang, 2017)

$$
\begin{aligned}
& \overline{\mathrm{C}}(\mathrm{x}, \mathrm{y}, \mathrm{s})=\frac{1-\exp \left(-\mathrm{t}_{\mathrm{s}} \mathrm{s}\right)}{\mathrm{b}}\left[\hat{\overline{\mathrm{C}}}(0)+2 \sum_{i=1}^{\mathrm{N}} \hat{\overline{\mathrm{C}}}(n) \sin \left(\frac{\mathrm{n} \pi \mathrm{y}}{\mathrm{b}}\right)\right] . \\
& \hat{\overline{\mathrm{C}}}(\mathrm{n})=\gamma \exp (\mathrm{rx}), \\
& \gamma=\frac{\mathrm{C}_{0} \mathrm{~b}}{\operatorname{sn} \pi}\left[\sin \left(\frac{\mathrm{n} \pi \mathrm{y}_{\mathrm{t}}}{\mathrm{b}}\right)-\sin \left(\frac{\mathrm{n} \pi \mathrm{y}_{\mathrm{b}}}{\mathrm{b}}\right)\right], \\
& \mathrm{r}=\frac{1}{2 \mathrm{D}_{\mathrm{x}}}\left(\mathrm{v}-\sqrt{\mathrm{v}^{2}+4 \mathrm{D}_{\mathrm{x}} \boldsymbol{\beta}}\right), \\
& \boldsymbol{\beta}=\mathrm{D}_{\mathrm{y}}\left(\frac{\mathrm{n} \pi}{\mathrm{b}}\right)^{2}+\Theta, \\
& \Theta=(\mathrm{s}+\lambda)+\frac{\rho_{b} \alpha \mathrm{k}_{\mathrm{d}} \mathrm{s}}{\theta[s+\alpha]} .
\end{aligned}
$$

where $\mathrm{x}$ and $\mathrm{y}$ are the coordinates in $\mathrm{x}$ and $\mathrm{y}$ directions respectively, $\mathrm{s}$ is Laplace complex variable, $\mathrm{C}_{0}$ is the concentration at contaminant source, $\mathrm{b}$ is the aquifer width. The physical constants and parameters for the corresponding analytical solution are summarized in table S. 1. To find the optimum value for $\alpha_{\mathrm{c}}$ and $\mathrm{q}$ in the Eq. (15), the sensitive analysis was done. In the analysis, first, the parameter $\mathrm{q}$ was varied from 0.8 to 1.2 for different $\alpha_{\mathrm{c}}$ and a relative error of concentration was defined as follows:

$$
\mathrm{RE}=\frac{\sum_{\mathrm{i}=0}^{\mathrm{n}}\left|\mathrm{C}_{\mathrm{i}}^{\text {exact }}-\mathrm{C}_{\mathrm{i}}^{\mathrm{RPCM}}\right|}{\sum_{\mathrm{i}=0}^{\mathrm{n}}\left|\mathrm{C}_{\mathrm{i}}^{\text {exact }}\right|}
$$

where $\mathrm{C}_{i}^{\text {exact }}$ and $\mathrm{C}_{\mathrm{i}}^{\mathrm{RPCM}}$ are contaminant concentration computed by the MQ-RBF and analytical solution, respectively. Fig. S. 2 demonstrates the variation of relative errors of concentration with shape parameters. It can be seen, the optimal shape parameter q occurred around 1 , and the minimum error is for $q=0.97$. Fig. S. 3a shows the effect of the shape parameter $\alpha_{\mathrm{c}}$ on the contaminant concentration profile at point $(30,7)$ for $q=0.97$ and compares with the exact solution. It is found that for the MQ$\mathrm{RBF}$, the values of the shape within the range of 3-5 gave very good accuracy. Among different shape parameters $\alpha_{\mathrm{c}}, \alpha_{\mathrm{c}}=4$ is the optimum value. Fig. S. $3 \mathrm{~b}$ compares contaminant concentration profile for the point located at $(30,7)$ for different shape parameters q for $\alpha_{\mathrm{c}}=4$. Fig. S. 4 compares contaminant concentration contours the MQ-RBF and analytical solutions for two-dimensional transport from a continuous line source in a confined aquifer. The simulation has done for $\mathrm{t}=200 \mathrm{~min}$ and the results are in good agreement.

\subsection{Model verification with the sandbox experiment}

A point source of $0.5 \% \mathrm{w} / \mathrm{v}$ potassium permanganate solution was constructed in a sandbox to map the change groundwater plume distribution over time. The sandbox is $150 \mathrm{~cm}$ in length, $38 \mathrm{~cm}$ in height, and has a thickness of $10 \mathrm{~cm}$ and was constructed 
Fig. 3: Schematic representation of sandbox experimental setup.

Fig. 4: The comparison between observed and MFree predicted plume.

with Plexiglass. The sandbox is $150 \mathrm{~cm}$ in length, $38 \mathrm{~cm}$ in height, and has a thickness of $10 \mathrm{~cm}$ and was constructed with Plexiglass. The sandbox has no-flow boundaries on top and bottom and the ends of the tanks consist of constant head tanks which are separated from the rest of the box by one impermeable wall and one perforated steel mesh filter to separate the sand from the head tanks. A peristaltic pump (Watson Marlow), which is capable of delivering a maximum of $42 \mathrm{~L} / \mathrm{h}$, was used to circulate water through the system. Fig.3 shows a schematic sketch of the used setup. The characteristics of the used sand including hydraulic conductivity were measured and given in Table S. 2 (Nijp et al., 2017; Sarki et al., 2014). To mitigate the creation of preferential pathways and air bubbles, the tank was filled with a layer of a few centimeters dry sand, after which tap water was added to saturate and cover the sand. More dry sand was layered over this now saturated sand, and itself covered with tap water. This process was repeated until the tank was full. The injection rate was $16 \mathrm{~L} / \mathrm{h}$; and $9 \mathrm{~L}$ total volume injected. The experiment was repeated three times, and presented results are the average results. Fig. 4 compares the observed permanganate plume in the tank and predicted plume at the same time after injection. Table S. 3 compares measured permanganate concentration at two different sampling points located at $(36,18.5) \mathrm{cm}$ and $(56,18.5) \mathrm{cm}$, with respect to the origin which is located at the bottom Corner of input end of tank, with Meshfree predicted concentration.

\section{Remediation design optimization using Genetic Algorithm}

Multi-objective optimisation (MOO) including multi-objective genetic algorithm can be utilised to address optimization problems related to groundwater. In this study, the multi-objective genetic algorithm is employed to seek the global optimisation of remediation design. The cost of remediation and the concentration of the contaminant are competitive functions which are considered as two objective functions. To find optimal design, GA simultaneously minimises the cost of the remediation process by the minimising the number of oxidant sources and contaminant concentration by maximising the region where contaminant concentration is equal-less than the desired final concentration. To achieve this goal, we have defined the following functions:

$$
\begin{aligned}
& \mathrm{GA} 1=\mathrm{TC}=\mathrm{n}_{\mathrm{OS}} * \mathrm{COS}, \\
& \mathrm{GA} 2=\Omega_{\mathrm{C}_{\mathrm{ARCC}}^{1}}=\left\{(\mathrm{x}, \mathrm{y}) \in \Omega: \mathrm{C}^{1} \leqslant \mathrm{C}_{\mathrm{ARCC}}^{1}\right\} .
\end{aligned}
$$

where $\mathrm{C}_{\mathrm{ARCC}}^{1}$ is the aimed remediation contaminant concentration, $\mathrm{TC}$ is the total cost of the remediation process, $\mathrm{n}_{\mathrm{OS}}$ is the number of the oxidant sources and COS denotes the cost of each oxidant source. To achieve the objective of the study, we wish 
to minimise GA1 and maximise GA2.

$$
\begin{aligned}
& \min \text { GA1, } \\
& \max \text { GA2. }
\end{aligned}
$$

by considering the following constraints:

1. The distance between oxidant sources

$$
\mathrm{d} \geq \mathrm{d}_{\mathrm{c}}
$$

where $\mathrm{d}=\sqrt{\left(\mathrm{x}_{\mathrm{i}}-\mathrm{x}_{\mathrm{j}}\right)^{2}+\left(\mathrm{y}_{\mathrm{i}}-\mathrm{y}_{\mathrm{j}}\right)^{2}}$ is actual distance between oxidant source $\mathrm{i}$ and $\mathrm{j}$ and $\mathrm{d}_{\mathrm{c}}$ is the critical distance between oxidant sources. The critical distance is the distance between two oxidant sources which their influence domain overlap more than $75 \%$. The influence domain is defined as a region in where the oxidant concentration reaches $15 \%$ of its initial concentration at the source after 50 days if it implements alone. The following function defines the influence domain which is used to define critical distance.

$$
\Omega_{\mathrm{C}_{20 \%}^{2}}^{\mathrm{t}=50 \text { days }}=\left\{(\mathrm{x}, \mathrm{y}) \in \Omega: \mathrm{C}^{2} \geqslant 15 \% \mathrm{C}_{0}^{2}\right\} .
$$

regarding our prior simulation, if a distance between sources is less than the critical distance then the contaminant concentration in the whole geometry is in many designs more than aimed remediation contaminant concentration.

2. The number of oxidant sources

$$
\mathrm{n}_{\mathrm{OS}} \leq 5
$$

where $n_{O S}$ is actual the number of oxidant sources.

\section{Results and Discussion}

The purpose of our numerical study is to find the optimum remediation design utilising permanganate. The aquifer domain is $500 \mathrm{~m}$ by $100 \mathrm{~m}$ with a relatively homogenous hydraulic conductivity. The oxidant sources have been considered to remediate the continuous line contaminant source and GA approach is used to find the optimum location and number of them concerning criteria presented in Section 5. The optimum shape parameter $\mathrm{q}=0.97$ and $4 . \mathrm{dc}$ with 12 nodes in every support domain were used in numerical approach. The same nodes distribution used for both flow model and the transport model. The longitudinal dispersivity $\alpha_{L}$ for this problem is considered 15 $\mathrm{m}$ and the transverse dispersivity $\alpha_{T}$ is taken as $10 \%$ of the longitudinal dispersivity. The functions presented by (Wolf, 2013; Yao et al., 2016) are modified for our study to simulate the oxidant release. The contaminant concentration at line source located at $\mathrm{x}=60 \mathrm{~m}, 20 \mathrm{~m} \leq \mathrm{y} \leq 80 \mathrm{~m}$ is $\mathrm{C}^{1}=275 \frac{\mathrm{mg}}{\mathrm{L}}$. Fig. 5a demonstrates the piezometric iso head contours. Fig. $5 \mathrm{~b}$ and $5 \mathrm{c}$ show the contaminant and oxidant concentration 
Fig. 5: a:piezometric head profile and contours, b: contaminant concentration profile, c: oxidant concentration profile.

Fig. 6: the contaminant concentration profile at observation point located at a) $(100,50) \mathrm{m}, \mathrm{b})(150,65) \mathrm{m}, \mathrm{c})$ $(300,55) \mathrm{m}$.

at different times. The simulations have been performed for 250 days with a time step of 0.004 day. Overall, the water head contours decreased from left to right, with mounding around the contaminant and the oxidant injection sources. As expected, the concentration of the contaminant in the regions closer to the oxidant sources is less than the farther regions, but with the increase of the distances from the oxidant sources it changes rapidly. The performance of the optimized design was compared with two different arbitrary design. In both designs, three oxidant sources were considered locating at $(90,30) \mathrm{m},(90,70)$ and $(150,50)$ in the first design and $(110,50) \mathrm{m},(110,30)$ and $(250,70)$ in the second design. Fig. 6 compares the contaminant concentration at three different observation points located at the $(100,50) \mathrm{m},(150,65) \mathrm{m}$ and $(300,55) \mathrm{m}$ at the downside of the stream for optimised design and arbitrary designs. The optimisation of remediation not only decreases the contaminant concentration at observation points but also it postpones the time in when the concentration begins to increase from zero in the observation points expects the second arbitrary design at the third observation point. The delay time was almost 12, 37 and 34 days in the first arbitrary design and 17, 48 and 4 days in the second arbitrary design for first, second and third observation points respectively. Furthermore, it can be translated that optimisation design reduces the remediation cost. Initial oxidant concentration needs to be adjusted $8 \%$ higher than the optimised value in the first arbitrary design and $11 \%$ higher for the second one. The levels were selected to attain the same concentrations of the contaminant in the models comparing to an optimised design. Choosing the same initial oxidant concentration leads to a higher number of oxidant sources. For instance, the same level of contaminant would be obtained by four oxidant sources locating at $(90,30),(90,70),(100,40)$ and $(100,60)$. In addition, it can be concluded that the far further from the centre line of the geometry the higher delay. In all observation points, the effect of optimization on the contaminant concentration is decreased with increasing the time. The contaminant concentration after 250 days was $17.1 \%, 21.8 \%$ and $22.4 \%$ in the first arbitrary design $48.8 \%, 57.8 \%$ and $-28.7 \%$ in the second arbitrary design for first, second and third observation points respectively, less than its values in the optimised design.

\section{Conclusion}

In this study, a multi quadratic radial basis function was used to simulate coupled groundwater flow and reactive transport of contaminant and oxidant in a porous aquifer. The sensitive analysis was done to find the optimum used shape parameter in MQ-RBFs with comparing the results with two-dimensional solute transport benchmark. The output from the model is compared to the results of sandbox experiment. The RSME error between measured and predicted permanganate concentration at two 
sample points for different times was less than 0.5, and it shows that the measured and predicted concentration are in good agreement. It was observed that the predicted permanganate concentration by the meshfree method shows good agreement with the measured values of the permanganate concentration in physical sandbox model. The genetic algorithm was used to find the optimum number and the optimum design of the oxidant sources regarding introduced criteria in section 5. The optimization has two different effects on the remediation process. It not only delays the reaching time of the contaminant to the downstream region but also it decreases the contaminant concentration in this area.

\section{Acknowledgement}

This work was completed as part of the REMEDIATE (Improved decision-making in contami- nated land site investigation and risk assessment) Marie-Curie Innovation Training Network. The network has received funding from the European Unions Horizon 2020 Programme for research, technological development and demonstration under grant agreement n. 643087. REMEDIATE is coordinated by the QUESTOR Centre at Queens University Belfast http://questor.qub.ac.uk/REMEDIATE/

\section{References}

An, D., Yang, Y., Jiang, Y., Xi, B., Bai, S., Li, M., Zhang, J., 2013. A new risk ranking method for groundwater contamination of hazardous waste landfills in china. Fresenius Environmental Bulletin 22 (8), 2371-2378.

Baú, D. A., Mayer, A. S., 2007. Data-worth analysis for multiobjective optimal design of pump-and-treat remediation systems. Advances in Water Resources 30 (8), 18151830 .

Bear, J., 1979. Hydraulics of groundwater. McGraw-Hill International Book Co.

Bear, J., 2007. Hydraulics of Groundwater. Dover Publications.

Bergillos, R. J., Lpez-Ruiz, A., Principal-Gmez, D., Ortega-Snchez, M., 2018. An integrated methodology to forecast the efficiency of nourishment strategies in eroding deltas. Science of The Total Environment 613-614, 1175-1184.

Bertolazzi, E., Manzini, G., 2004. A finite volume method for transport of contaminants in porous media. Applied Numerical Mathematics 49 (3), 291-305.

Chen, Y., Lu, H., Li, J., Ren, L., He, L., 2017. A leader-follower-interactive method for regional water resources management with considering multiple water demands and eco-environmental constraints. Journal of Hydrology 548 (Supplement C), 121-134.

Elimelech, M., Phillip, W. A., 2011. The future of seawater desalination: Energy, technology, and the environment. Science 333 (6043), 712-717. 
EU, 2007. Addressing the challenge of water scarcity and droughts in the european union. Communication from the Commission to the European Parliament and the Council, COM (2007) 414.

Freeze, R., Cherry, J., 1979. Groundwater. Prentice-Hall.

Goltz, M., Huang, J., 2017. Modeling. John Wiley \& Sons, Inc., pp. 1-17.

GR, L., 1999. A point assembly method for stress analysis for solid, in impact response of materials \& structures. V. P. W. Shim et al. eds, 475-480.

Guneshwor Singh, L., Eldho, T. I., Vinod Kumar, A., 2016. Coupled groundwater flow and contaminant transport simulation in a confined aquifer using meshfree radial point collocation method (rpcm). Engineering Analysis with Boundary Elements 66 (Supplement C), 20-33.

Hadley, P. W., Newell, C. J., 2012. Groundwater remediation: The next 30 years. Ground Water 50 (5), 669-678.

Hardy, R. L., 1971. Multiquadric equations of topography and other irregular surfaces. Journal of Geophysical Research 76 (8), 1905-\&.

He, L., Huang, G. H., Lu, H. W., 2008a. A simulation-based fuzzy chance-constrained programming model for optimal groundwater remediation under uncertainty. Advances in Water Resources 31 (12), 1622-1635.

He, L., Huang, G. H., Lu, H. W., 2009. A coupled simulation-optimization approach for groundwater remediation design under uncertainty: An application to a petroleumcontaminated site. Environmental Pollution 157 (8), 2485-2492.

He, L., Huang, G.-h., Lu, H.-w., Zeng, G.-m., 2008b. Optimization of surfactantenhanced aquifer remediation for a laboratory btex system under parameter uncertainty. Environmental Science \& Technology 42 (6), 2009-2014.

Holland, J. H., 1992. Adaptation in Natural and Artificial Systems: An Introductory Analysis with Applications to Biology, Control and Artificial Intelligence. MIT Press.

Huang, G., 1992. A stepwise cluster analysis method for predicting air quality in an urban environment. Atmospheric Environment. Part B. Urban Atmosphere 26 (3), 349-357.

Illman, W. A., Berg, S. J., Yeh, T.-C. J., 2012. Comparison of approaches for predicting solute transport: Sandbox experiments. Ground Water 50 (3), 421-431.

JG Wang, G. L., 2002. A point interpolation meshless method based on radial basis functions. International Journal for Numerical Methods in Engineering 54 (11), 1623-1648. 
Kansa, E. J., 1990. Multiquadricsa scattered data approximation scheme with applications to computational fluid-dynamicsii solutions to parabolic, hyperbolic and elliptic partial differential equations. Computers \& Mathematics with Applications 19 (8), 147-161.

Leo, C. J., Booker, J. R., 1998. A boundary element method for analysis of contaminant transport in fractured and non-fractured porous media. Computers and Geotechnics 23 (3), 165-181.

Liu, G., Gu, Y., 2005. An Introduction to Meshfree Methods and Their Programming. Springer Netherlands.

Lpez-Ruiz, A., Bergillos, R. J., Raffo-Caballero, J. M., Ortega-Snchez, M., 2018. Towards an optimum design of wave energy converter arrays through an integrated approach of life cycle performance and operational capacity. Applied Energy 209, 20-32.

Meenal, M., Eldho, T. I., 2011. Simulation of groundwater flow in unconfined aquifer using meshfree point collocation method. Engineering Analysis with Boundary Elements 35 (4), 700-707.

Meenal, M., Eldho, T. I., 2012. Two-dimensional contaminant transport modeling using meshfree point collocation method $(\mathrm{pcm})$. Engineering Analysis with Boundary Elements 36 (4), 551-561.

Nijp, J. J., Metselaar, K., Limpens, J., Gooren, H. P. A., van der Zee, S. E. A. T. M., 2017. A modification of the constant-head permeameter to measure saturated hydraulic conductivity of highly permeable media. MethodsX 4, 134-142.

Praveen Kumar, R., Dodagoudar, G. R., 2008. Two-dimensional modelling of contaminant transport through saturated porous media using the radial point interpolation method (rpim). Hydrogeology Journal 16 (8), 1497.

Ricken, T., Sindern, A., Bluhm, J., Widmann, R., Denecke, M., Gehrke, T., Schmidt, T., 2014. Concentration driven phase transitions in multiphase porous media with application to methane oxidation in landfill cover layers. ZAMM - Journal of Applied Mathematics and Mechanics / Zeitschrift fr Angewandte Mathematik und Mechanik 94 (78), 609-622.

Rippa, S., 1999. An algorithm for selecting a good value for the parameter $\mathrm{c}$ in radial basis function interpolation. Advances in Computational Mathematics 11 (2-3), 193210 .

Robeck, M., Ricken, T., Widmann, R., 2011. A finite element simulation of biological conversion processes in landfills. Waste Management 31 (4), 663-669.

Sarki, A., Mirjat, M. S., Mahessar, A. A., Kori, S. M., Qureshi, A. L., 2014. Determination of saturated hydraulic conductivity of different soil texture materials. IOSR Journal of Agriculture and Veterinary Science 7 (12), 56-62. 
Schaback, R., Wendland, H., 2000. Adaptive greedy techniques for approximate solution of large rbf systems. Numerical Algorithms 24 (3), 239-254.

SCHMUCK, S., WERNER, D., WIDMANN, R., RICKEN, T., 2016. Depsim: Numerical 3d-simulation of the water, gas and solid phase in a landfill. International Journal of Sustainable Development and Planning 11 (5), 694 - 699.

Seyedpour, S. M., Ricken, T., 2016. Modeling of contaminant migration in groundwater: A continuum mechanical approach using in the theory of porous media. PAMM 16 (1), 487-488.

Sharma, H. D., Reddy, K. R., 2004. Geoenvironmental engineering: site remediation, waste containment, and emerging waste management technologies. John Wiley \& Sons, Inc.

Sinha, E., Minsker, B. S., 2007. Multiscale island injection genetic algorithms for groundwater remediation. Advances in Water Resources 30 (9), 1933-1942.

Sotomayor, G., Hampel, H., Vzquez, R. F., 2018. Water quality assessment with emphasis in parameter optimisation using pattern recognition methods and genetic algorithm. Water research 130, 353-362.

Stroo, H. F., Leeson, A., Ward, C. H., 2012. Bioaugmentation for groundwater remediation. Vol. 5. Springer Science \& Business Media.

Sun, N.-Z., Sun, A., 2013. Mathematical modeling of groundwater pollution. Springer Science \& Business Media.

Tam, E. K. L., Byer, P. H., 2002. Remediation of contaminated lands: a decision methodology for site owners. Journal of Environmental Management 64 (4), 387400.

Tatalovich, M. E., Lee, K. Y., Chrysikopoulos, C. V., 2000. Modeling the transport of contaminants originating from the dissolution of dnapl pools in aquifers in the presence of dissolved humic substances. Transport in Porous Media 38 (1), 93-115.

Tian, N., Sun, J., Xu, W., Lai, C.-H., 2011. An improved quantum-behaved particle swarm optimization with perturbation operator and its application in estimating groundwater contaminant source. Inverse Problems in Science and Engineering 19 (2), 181-202.

Varghese, G. K., Alappat, B. J., Samad, M. S. A., 2015. Mt3dms and genetic algorithm in environmental forensic investigations. Procedia Environmental Sciences 30, 8590.

Wang, H., Anderson, M. P., 1982. Introduction to groundwater modeling : finite difference and finite element methods. W.H. Freeman, San Francisco.

Wang, J. G., Liu, G. R., 2002. On the optimal shape parameters of radial basis functions used for 2-d meshless methods. Computer Methods in Applied Mechanics and Engineering 191 (23-24), 2611-2630. 
Wolf, G., 2013. Slow release permanganate cylinders for sustainable in situ chemical oxidation: Development of a conceptual design tool (m.s. thesis),. Clarkson University, Potsdam, NY.

Wright, G., 2003. Radial Basis Function Interpolation: Numerical and Analytical Developments. University of Colorado.

WWAP, 2015. The united nations world water development report 2015: water for a sustainable world. United Nations World Water Assessment Programme.

Yao, G., Bliss, K. M., Crimi, M., Fowler, K. R., Clark-Stone, J., Li, W., Evans, P. J., 2016. Radial basis function simulation of slow-release permanganate for groundwater remediation via oxidation. Journal of Computational and Applied Mathematics 307 (Supplement C), 235-247.

Zhang, S., Mao, G., Crittenden, J., Liu, X., Du, H., 2017. Groundwater remediation from the past to the future: A bibliometric analysis. Water Research 119 (Supplement C), 114-125.

Zheng, C., Bennett, G. D., 2002. Applied contaminant transport modeling. Vol. 2. Wiley-Interscience New York. 

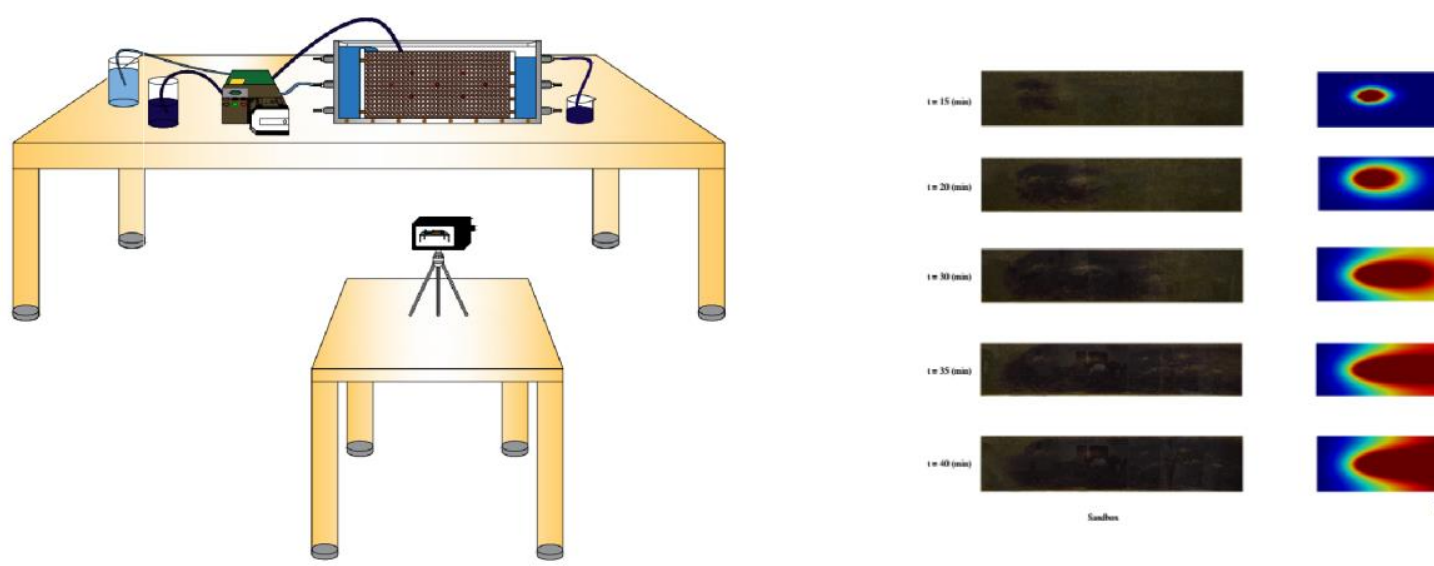

$\mathrm{t}=50$ days

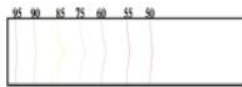

0

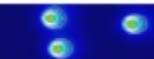

$t=100$ days

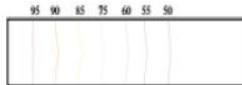

0

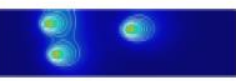

$\mathrm{t}=150$ days
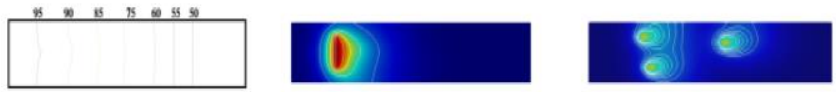

$\mathrm{t}=200$ days



(1)
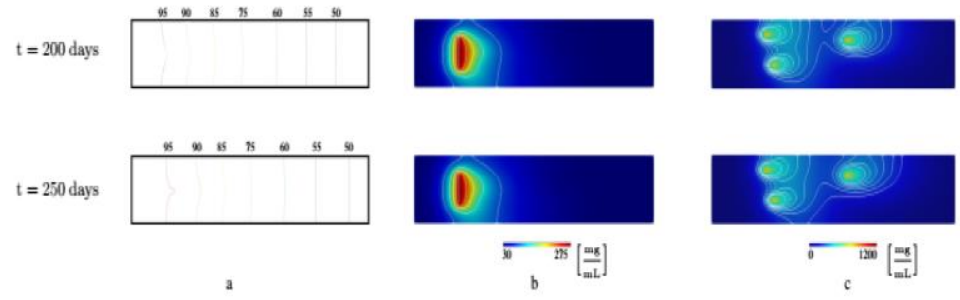


\section{Highlights}

- MRBF Meshfree model to simulate coupled groundwater flow and contaminant transport is proposed.

- The proposed model is validated with an analytical solution to find optimum shape parameter.

- The model results is compared with the results of a physical sandbox.

- The multi-objective Genetic Algorithm approach is used to find the optimum design of the remediation. 


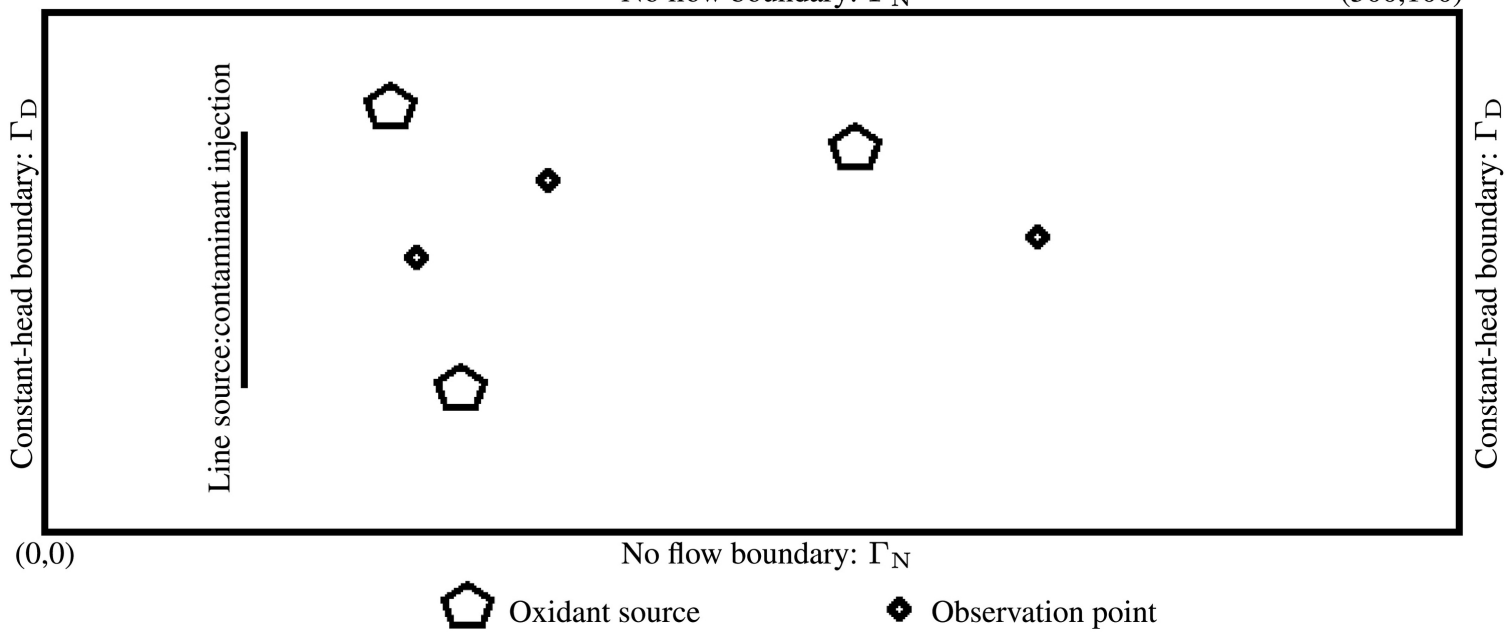

Figure 1 


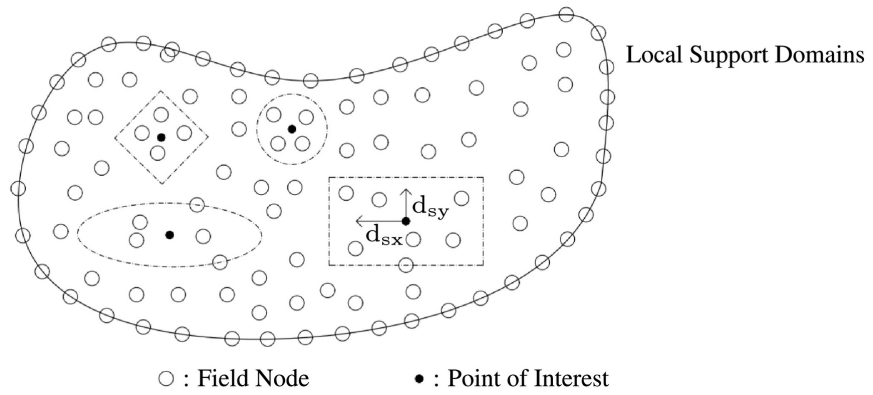

Figure 2 


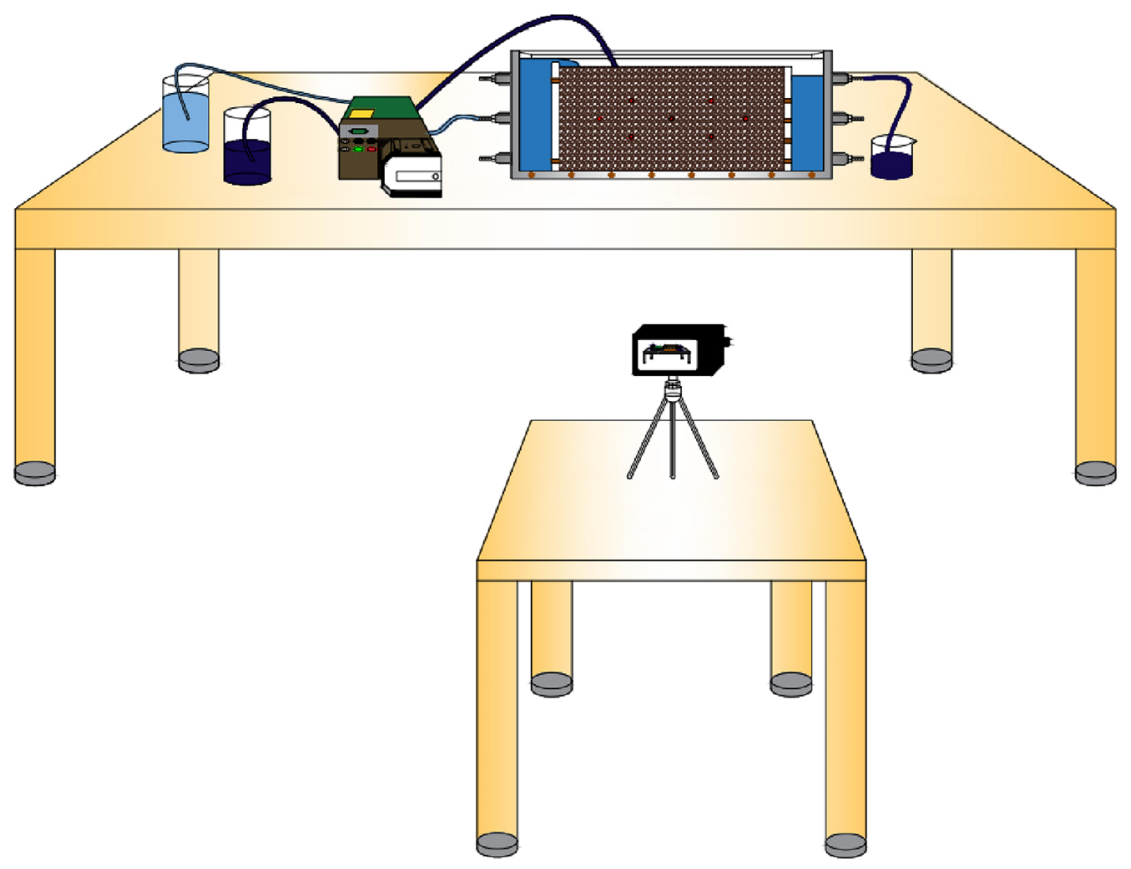

Figure 3 

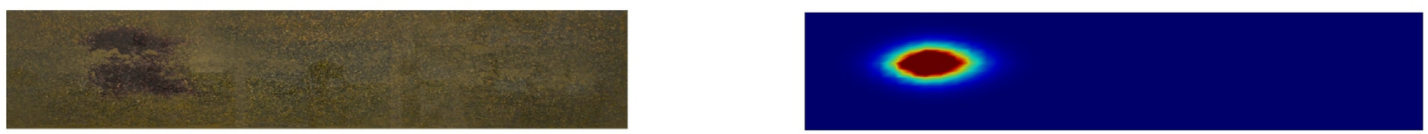

$\mathrm{t}=20(\min )$
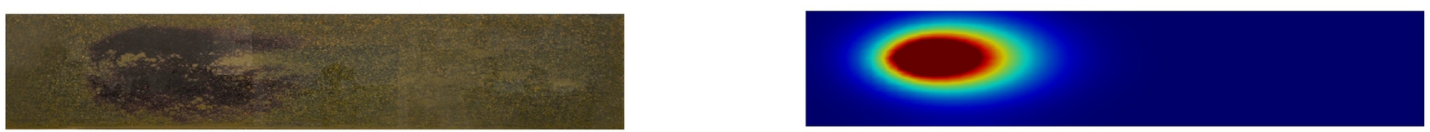

$\mathrm{t}=30(\mathrm{~min})$
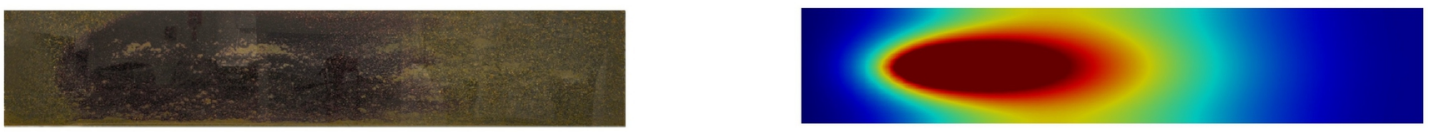

$\mathrm{t}=35(\mathrm{~min})$
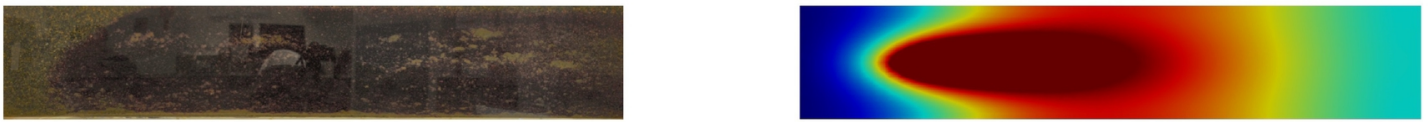

$\mathrm{t}=40(\mathrm{~min})$
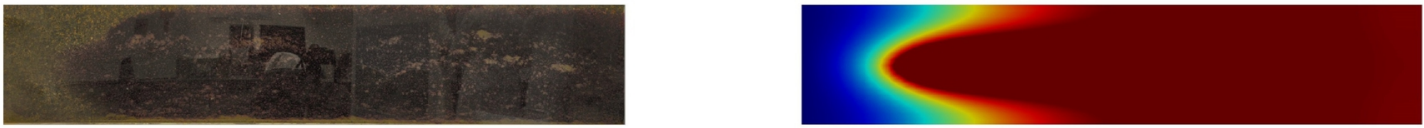

$\overline{\substack{\text { MeshFree } \\ \text { 3800 }}}\left[\frac{\mathrm{mg}}{\mathrm{L}}\right]$

Figure 4 


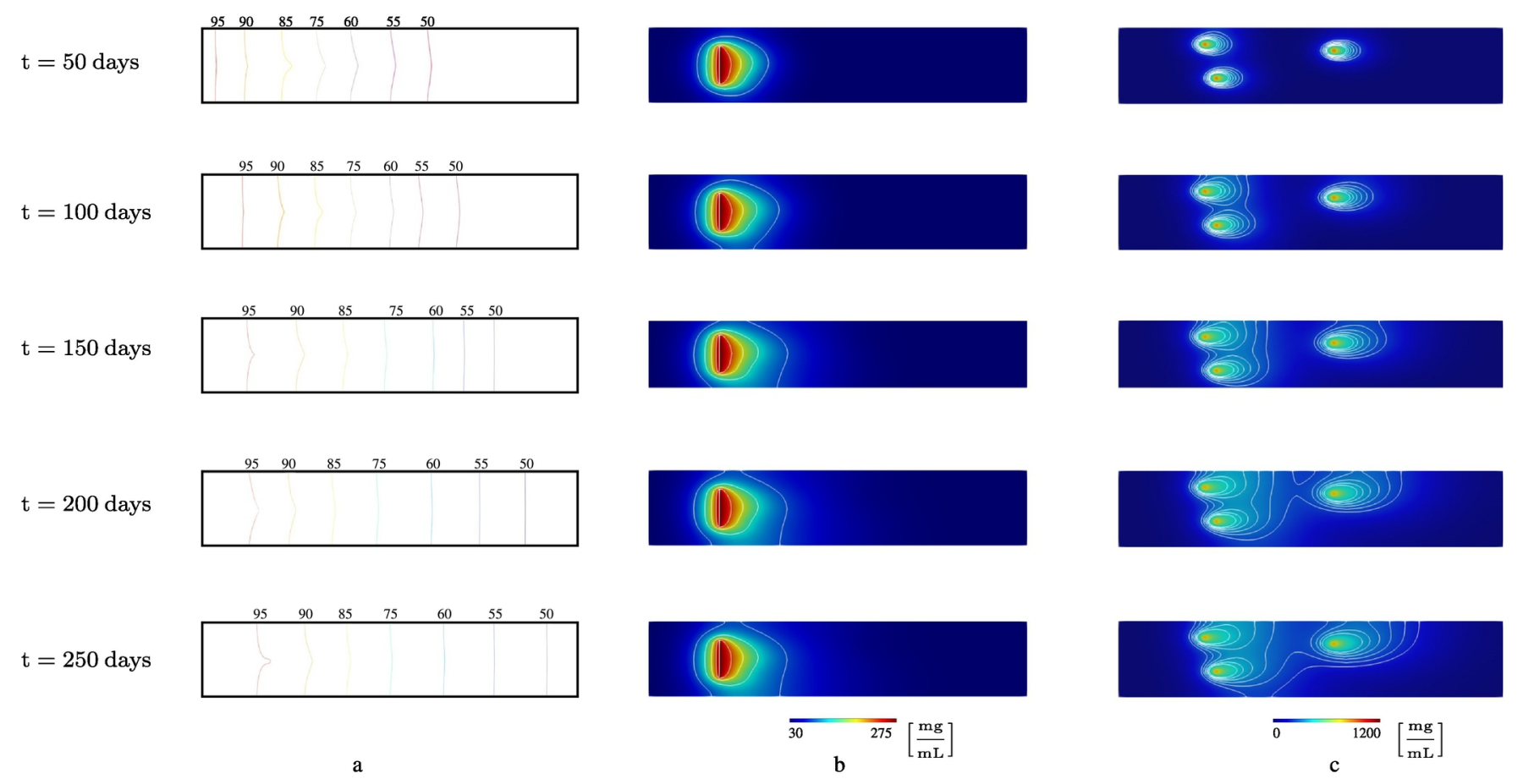

Figure 5 

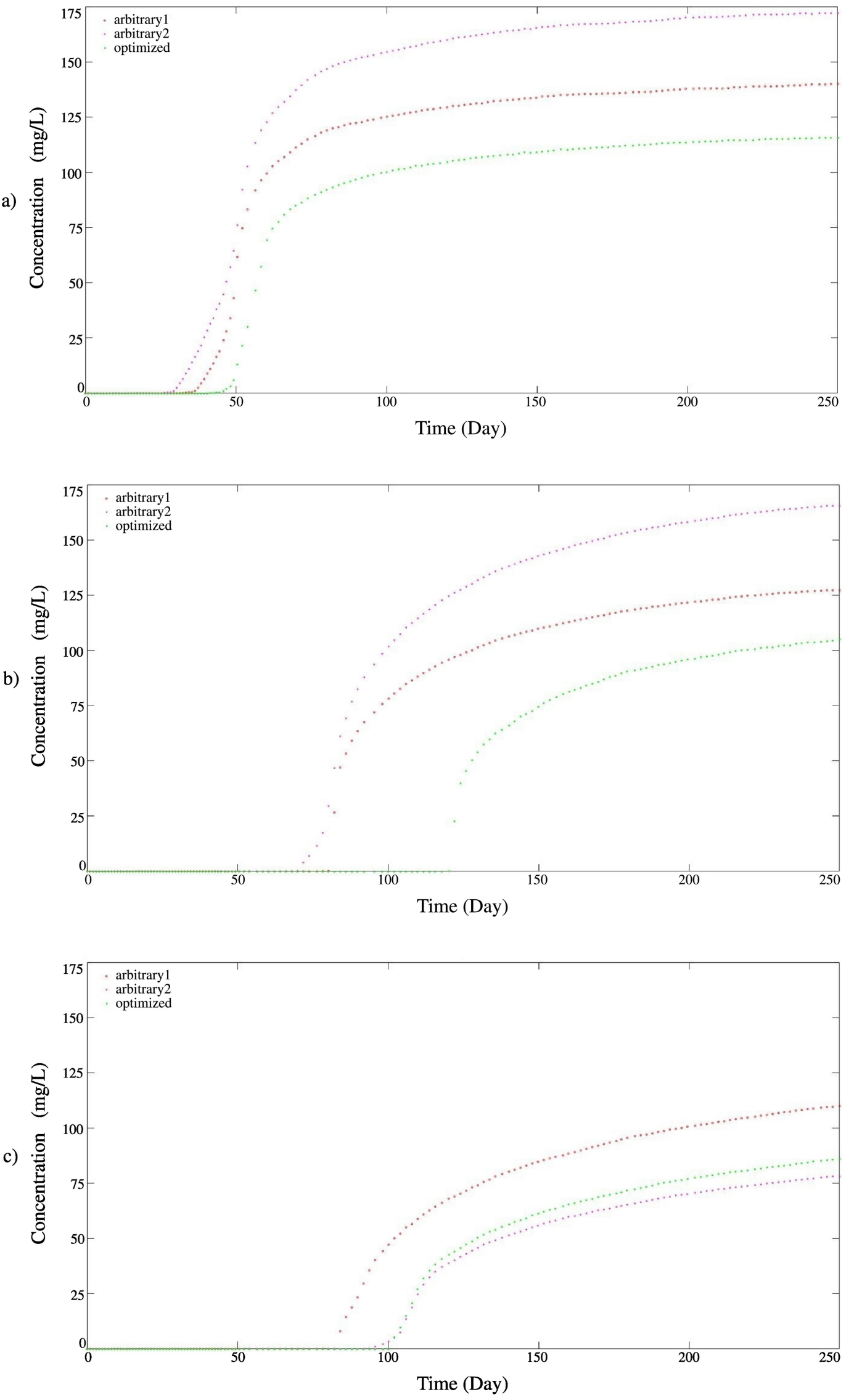

Figure 6 